\title{
Gastrointestinal haemorrhage from small bowel duplication
}

\author{
M. J. JoHNSTONE \\ M.B., Ch.B.
}

\author{
J. F. ClegG \\ M.A., F.R.C.S.
}

Department of Surgery, Leighton Hospital, Crewe

\begin{abstract}
Summary
A case is reported of duplication of the small bowel presenting with gastrointestinal haemorrhage. This is the first reported case in an adult. A review of the literature has been made and the pathogenesis discussed.
\end{abstract}

\section{Case history}

A 44-year-old Caucasian male presented in August 1974 with an 8-day history of passing melaena stools and feeling faint. He had no other gastrointestinal symptoms but previously had passed melaena stools at the ages of 15 and 28 years. On both occasions no abnormality was found. His pulse rate was $80 / \mathrm{min}$ and blood pressure $100 / 70$ $\mathrm{mmHg}(13 \cdot 3 / 9 \cdot 3 \mathrm{kPa})$. Abdominal examination was normal apart from the finding of melaena stool on rectal examination. His haemoglobin was $8.4 \mathrm{~g} / \mathrm{dl}$. He was given an 11-pint (5.9 1) blood transfusion before the bleeding ceased. Subsequent investigation of the gastrointestinal tract revealed a normal barium meal with follow-through and a normal barium enema together with normal liver function tests. Gastroduodenoscopy at the time of admission was normal. In view of the history, laparotomy was undertaken and revealed a duplication of $11.5 \mathrm{~cm}$ of the proximal jejunum. The proximal end of the duplication communicated with the normal jejunum and the distal portion ended blindly in the mesentery. The duplicated lumen was lined throughout by gastric mucosa, mostly of body type, and at the junction of the normal intestine and the duplicated segment a small shallow ulcer was present. The duplicated segment possessed well formed muscle coats and a surplus of ectopic pancreatic tissue was present in the submucosa (Fig. 1). The duplicated segment was excised and an end-to-end anastomosis performed. Subsequently the patient made a good recovery.

\section{Discussion}

Duplication of the gastrointestinal tract is a rare but well recognized cause of gastrointestinal bleeding and the 'acute abdomen' in children (Gross, Holcomb and Farber, 1952; Mellish and Koop, 1961; Sieber, 1956; Baus, Forshall and Rickham, 1960;
Forshall, 1961). In the adult, however, it has only been reported on two occasions, both involving the large intestine (Rigg, 1974; Reilly, Weismann and Dyke, 1968) and has never been seen in the small intestine. According to Brewer (1957) the group of anomalies comprising the enterogenous cysts, diverticulae and duplications are divisible into two groups on the basis of their embryological origin. One group is that of the spherical cysts. These are derived from the true diverticulae which are frequently found projecting from the ventral or antemesenteric surface of the intestine in the embryo at the eighth to ninth week and are normally later absorbed (Brewer, 1944). Abnormally they continue to grow. If constricted by the intestinal muscle they bulge within the lumen, but if they pierce between the muscle layers, outward expansion is not limited and they become large cysts attached to the intestine.

The other group consists of tubular structures representing true duplications. According to RiosDalenz, Kress and Montgomery (1965) a clear embryological explanation for the origin of duplication of the intestinal track is lacking. Brewer (1957) suggested that a few of the spherical and most of the tubular structures representing true duplication originate from the abnormal persistence of the vacuoles normally present among the massed cells of the 'solid stage' of intestinal growth. This growth phenomenon occurs in the embryo of the sixth and seventh week of uterine development. By the confluence of the chain of vacuoles a new channel is formed parallel to the original lumen. Since the duplication develops within the intestine, the outer wall of the duplicated portion always contains all the tissue layers of the normal intestine. The duplicated lumen usually lies between the leaves of mesentery but may be entirely separated, with a mesentery of its own formed by splitting of the original. It may open into the lumen at one or more places. In the duplicated segment the mucosa tends to resemble that of the parent type, but in bulbous or cystic portions it changes to the cystic type. Many other theories exist. Stowens (1959) postulated that the appearance of this lesion at an early stage is due to incomplete separation of the primitive gut from the notochord. Holt and McIntosh (1953) suggested 


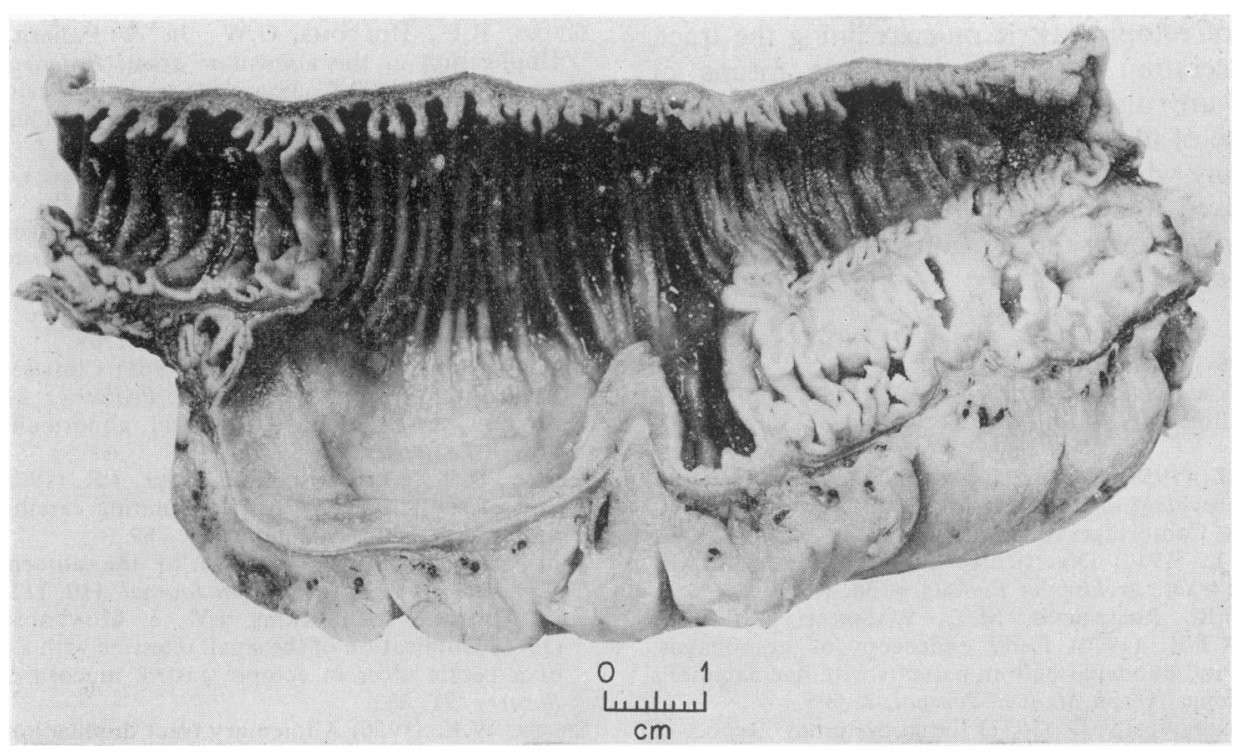

FIG. 1. Duplication of the proximal jejunum.

that duplication is the result of midline splitting of the primordial tissue, whereas Ravitch (1953) stated that doubling of the colon and the genitourinary apparatus can be explained as a form of partial twinning or incomplete formation of two individuals. Pathogenesis of duplication of the gastrointestinal tract is speculative and it undoubtedly occurs more frequently at certain sites, the commonest being the ileum. Dohn and Povlsen reviewed the literature and found that $50 \%$ of gastrointestinal duplications appeared in the ileum and this figure has been supported by the findings of Basu et al. (1960) and Gross et al. (1952).

Massive upper gastrointestinal bleeding is amongst the most exacting conditions which the surgeon is called upon to treat. Refinements in diagnosis have made such treatment as blind gastrectomy a relic of the past. Radiological investigation is notoriously inaccurate in this respect and barium studies in this case were uninformative. At least $20 \%$ of simple peptic ulcers are missed by conventional barium meal (Irving and Northfield, 1976). In a trial by Hoare (1975) only thirty-nine out of 105 radiological examinations in patients suffering from gastrointestinal bleeding yielded a probable cause. The success rate for showing rare lesions in the small bowel by small bowel follow-through examination is even less accurate. The use of the fluoroscein string test (Kay, 1962) has not stood the test of time, neither has the use of ${ }^{51} \mathrm{Cr}$-labelled red blood cells been accurate in identifying the bleeding site. The two current investigations in vogue for elucidating this difficult diagnostic problem are fibre-optic endoscopy and superior mesenteric angiography. Endoscopic examination is more accurate than barium meal in finding bleeding lesions (Cotton, 1973). In the authors' unit the examination is performed under general anaesthetic using tracheal intubation by a consultant anaesthetist. This technique is much faster and safer than by other means. The quality of the view is much improved and there is little risk of endotracheal aspiration. All these points are important and far outweigh the small risk of a general anaesthetic. Superior mesenteric angiography is only rarely used to detect the source of gastrointestinal bleeding in this country. The lesion must be actively bleeding at the time of the examination, but it has been claimed that such a small amount as $0.5 \mathrm{ml} / \mathrm{min}$ loss can be detected in the bowel and the site identified. Irving and Northfield (1976) have shown that emergency arteriography has a diagnostic yield of $75-77 \%$, which is similar to that of barium meal. Nevertheless it is more time-consuming than endoscopy and also has a proved morbidity and mortality. It should therefore be reserved until all other diagnostic techniques fail.

\section{Conclusion}

Small bowel duplication is a rare cause of gastrointestinal haemorrhage. Nevertheless, owing to the 
presence of ectopic gastric mucosa lining the tract, peptic ulceration can occur. Possible means of diagnosis are discussed and a plea is made for greater use of fibre-optic endoscopy and mesenteric angiography when appropriate. It is hoped, but as yet unproved, that the better use of modern diagnostic aids will lower the mortality of gastrointestinal haemorrhage.

\section{References}

Basu, R., Forshall, I. \& Rickham, P.P. (1960) Duplication of the alimentary tract. British Journal of Surgery, 47, 477.

BREWER, J.L. (1957) Congenital Anomalies of the VisceraTheir Embryological Basis, 1st edn, p. 68. Harvard University Press, Cambridge, Massachusetts.

BREWER, J.L. (1944) Diverticulae and duplications of the intestinal tract. Archives of Pathology, 38, 132.

Cotton, P.B., Rosenberg, M.T., Waldram, R.P.L. \& Axon, A.T.R. (1973) Early endoscopy of oesophagus, stomach and duodenal bulb in patients with haematemesis and melaena. British Medical Journal, 2, 505.

Dohn, K. \& Povlsen, D. (1971) Enterocystomas. Report of six cases. Acta chirurgica scandinavica, 102, 21.

Forshall, I. (1961) Duplication of the intestinal tract. Postgraduate Medical Journal, 37, 570.
Gross, R.E., Holcomb, G.W., JR \& Farber, S. (1952) Duplication of the alimentary tract. Pediatrics, 9, 449.

HoARe, A.M. (1975) Comparative study between endoscopy and radiology in acute upper gastrointestinal haemorrhage. British Medical Journal, 1, 27.

Holt, L.E. \& McIntosh, R. (1953) Pediatrics, 12th edn, p. 138. Appleton Century Croft, New York.

IRVING, J.D. \& NoRTHFIELD, T.C. (1976) Emergency arteriography in acute gastrointestinal bleeding. British Medical Journal, 1, 929.

KAY, A.W. (1962) Management of obscure alimentary bleeding. British Medical Journal, 1, 1709.

Mellish, R.W.P. \& KooP, E.E. (1961) Clinical manifestations of duplication of the bowel. Pediatrics, 27, 397.

Ravitch, M.M. (1953) Congenital abnormalities of the bowel. Pediatrics, 27, 397.

Reilly, H.F., WeismanN, R. \& Dyke, J.R. (1968) Duplication of the alimentary tract simulating carcinoma of the descending colon. Radiology, 90, 769.

RigG, B.N. (1974) Duplication of the alimentary tract Canadian Medical Association Journal, 110, 1124.

Rios, Dalenz, J.C., Kress, J.W. \& Montgomery, C.G (1965) Duplication of the small intestine with a perforation of a peptic ulcer in ectopic gastric mucosa. Archives of Surgery, 91, 863.

Sieber, W.K. (1956) Alimentary tract duplications. Archives of Surgery, 73, 383.

Stowens, D. (1959) Pediatric Pathology. 1st edn, p. 469 Williams and Williams Co., Baltimore.

\title{
Carcinoma of the lung presenting with a myeloproliferative disorder. A report of two patients
}

\author{
M. B. McIllmurray \\ M.B., M.R.C.P.
}

\author{
D. R. RYRIE \\ M.B., F.C.R.Path., M.R.C.P.
}

\author{
J. FLETCHER \\ M.D., F.R.C.P.
}

Departments of Medicine and Clinical Haematology, City Hospital, Hucknall Road, Nottingham

\begin{abstract}
Summary
A myeloproliferative disorder, similar to agnogenic myeloid metaplasia, has been described in patients with cancer. Two patients with carcinoma of the lung are described who presented with such a disorder but in whom there was no evidence of bone marrow fibrosis and in one of whom there was no evidence of bone marrow infiltration by tumour. The possible mechanism of this association is discussed.
\end{abstract}

\section{Introduction}

Bone marrow replacement by tumour is occasionally associated with the appearance of immature cells in the peripheral blood. Rarely, this is accompanied by marrow fibrosis and extramedullary haemopoiesis and simulates the clinical picture of agnogenic myeloid metaplasia. The explanation for this is unknown, for the changes are often absent in patients with extensive involvement and present in patients where involvement is slight.

This report describes two patients who presented with a disorder of blood cell production in association with a carcinoma of the lung and in both of whom post-mortem examination'showed evidence of haemopoiesis in the spleen but no evidence of bone marrow fibrosis, and in one of whom the bone marrow did not appear to be infiltrated by tumour.

\section{Case 1}

A 65-year-old smoker complained of lethargy, 